\title{
AUTOPHAGY IN HEPATOCYTES AND ERYTHROPOIETIC CELLS ISOLATED FROM THE TWENTY-ONE DAY OLD RAT EMBRYO*
}

\author{
A. L. KovÁcs, ${ }^{* *}$ A. EldiB and Ágnes Telbisz \\ Department of General Zoology, Eötvös Loránd University, \\ P.O. Box 330, H-1445 Budapest, Hungary \\ (Received: January 10, 2001; accepted: March 2, 2001)
}

\begin{abstract}
Liver cells of the twenty-one day old rat embryo are isolated by a modified method and autophagy is studied in them by electron microscopic morphology and morphometry. Immediately after isolation or $2.5 \mathrm{~h}$ incubation in nutrient-free medium, embryonic hepatocytes contain high amount of glycogen and only very few autophagic vacuoles. In contrast, all glycogen is lost and $15 \%$ of the cytoplasmic volume is occupied by late autophagic vacuoles in hepatocytes after $18 \mathrm{~h}$ in the same medium. Presence of 3methyladenine in the latter case inhibits both the loss of glycogen and the appearance of autophagic vacuoles while enlarging the multivesicular body compartment. Our findings reveal major differences between isolated embryonic and adult hepatocytes concerning autophagy. Several types of autophagic vacuoles are described in the cell types of the erythropoietic cell lineage. This means that autophagy is an integral part of erythropoiesis not only in bone marrow, but also in embryonic liver that is investigated here for the first time from this point of view. The presence of unclosed isolation membranes and the predominance of early autophagic vacuoles in reticulocytes indicates that the molecular machinery of segregation is still active in this functionally and structurally highly reduced cell type.
\end{abstract}

Keywords: Segregation - 3-methyladenine - multivesicular body - glycogen - reticulocyte

\section{INTRODUCTION}

Autophagy (also called macroautophagy) is an intracellular process whereby the cells isolate and subsequently degrade portions of their own cytoplasm. The isolation (segregation, sequestration) is carried out by a special membrane (segregation or isolation membrane) and the resulting body is called autophagosome. After this socalled prelysosomal stage of the process the autophagosome is transformed into an autolysosome by fusing with primary or secondary lysosome. The breakdown of the sequestered material into molecular components takes place in the second, lysosomal phase (for reviews see: $[2,4,14,16,22]$ ). The common expression for autophago-

\footnotetext{
*Dedicated to Professor János Kovács on the occasion of his 70th birthday.

**Corresponding author; e-mail: alkova@cerberus.elte.hu
} 
somes and autolysosomes is autophagic vacuoles (AVs). The lysosomal part of autophagy is rather well known and researchers agree even in most details of it. However, the prelysosomal part and its initial event, the autophagic segregation is largely unexplored. Autophagy seems to be (at least potentially) present in most (perhaps all) types of eucaryotic cells from yeasts to mammalian neurones. This persistence in evolution points to a hitherto unrecognised general significance of autophagy in the function of cells. The prelysosomal part of autophagy, the segregation, seems to involve a so far completely unknown machinery of membrane transformation and/or (re)organisation $[6,12,13,16]$. Only the most recent results with mutant yeast cells have opened up the possibility to approach this problem with the powerful new methods of molecular genetics (for review see: [11]).

In spite of the progress at the molecular level, much remains to be described by traditional methods. The diversity of effects, chemicals or other variables that seem to be related with autophagy is perplexing. Presence of autophagic vacuoles has been described in a large number of pathological and physiological processes although their significance have still remained largely obscure. In addition, autophagy has been demonstrated in relation to functional changes of cells and to cell death during ontogenesis [3] and recent studies have shown alterations of autophagic activity during carcinogenesis $[10,19]$.

Only a few types of cells have been used as objects for systematic investigation of autophagy. As different cell types have different morphology, physiology and development, comparative studies may offer possibilities to find out specific and general features of autophagy as well as new aspects of its mechanism, regulation, developmental, physiological and pathological role. The best-studied cell type with regard to autophagy is the adult hepatocyte. However, even in case of liver cells no comparative studies of autophagy during ontogenesis have been carried out.

Adult hepatocytes react to the isolation procedure and the subsequent in vitro conditions with enhanced autophagy [22]. A fundamental difference between the liver cells of mammalian adults and embryos is that the latter ones are under the protection of the mother's body which may modify their reaction to autophagic stimuli. To achieve a reliable comparison we have developed a method of isolation and subsequent incubation of embryonic liver cells that is similar to those used for adult livers. As the embryonic liver carries out substantial hematopoietic functions, various cell types of it can be handled together in vitro producing comparative data on their autophagic reactivity under the same in vitro conditions. Autophagy in erythropoietic cells has so far been studied only in adult systems [7-9]. In this publication we describe the technique of cell isolation and characterise autophagy using electron microscopic morphology and morphometry in freshly isolated and in $18 \mathrm{~h}$ primary culture of the liver cells of 21-day-old rat embryo including hepatocytes and cells of the erythropoietic lineage. 


\section{MATERIALS AND METHODS}

\section{Timed pregnancies}

The Long-Evans rat mothers used in our experiments were fed by a standard laboratory diet (LATI, Gödöllő, Hungary) and had access to water ad libitum. For timed pregnancies we put together one male rat with 4 females. We observed the result in the next morning as described below. Usually, we got two positive results in four or five days. If we wanted to be absolutely sure of positive result in one week we started with two groups. Mating is most likely to take place after the onset of darkness, e.g., in late evening hours. The feasible time of observation is next morning. Successful mating is counted next morning as the 12 th hour of pregnancy. A widespread method in the literature to decide the date of successful mating is the observation of copulation plug in the vagina of females. However, we found vaginal plug in rare occasions and observed that it can fall out very easily making it an unreliable indicator of mating. However, the inspection of the fluid after rinsing the vagina with balanced salt solution (BSS) gave good results. In the lavage either complete sperm cells, or separate spermheads+necks and tails could be readily seen in phase contrast microscope; even normal light microscope can give satisfactory result, but the sperm heads and tails are more difficult to identify with certainty.

\section{Preparation of liver from the embryos}

Pregnant rats at day 21 were anaesthetised with ether (special quality for narcosis, Asid Bonz u. Sohn GmbH, Böblingen, Hoechst AG, Frankfurt am Main). In cases when sterile samples were needed the procedure was the following. The abdomen was carefully shaved by an electric shaver (Kuno Moser GmbH, Germany) and the hair (which is the most dangerous source of contamination) simultaneously removed by a vacuum cleaner. The shaved abdomen was swabbed with $70 \%$ ethyl alcohol and the animal was taken into a laminar airflow box (horizontal air flow, BL900 type, Debreceni Finommechanikai Vállalat, Hungary) for sterile operation. The uterus containing the embryos was put into sterile physiological saline to wash out blood. The embryos were released by cutting the uterine wall, the embryo was taken out and the placenta removed.

\section{Liver cell isolation, incubation and short-term primary culture}

The following method of cell isolation from embryonic liver is based on the principles of the two-step collagenase perfusion method of Seglen [20] for isolating adult rat liver cells. For liver cell isolation the embryos were collected in $\mathrm{Ca}^{++}$-free BSS of Dulbecco or Hanks [1] in a Petri dish. Livers were separated and collected in an other Petri dish, cut into small cubes (with approximately 2-4 $\mu \mathrm{m}^{3}$ dimensions) in $\mathrm{Ca}^{++}$- 
free BSS containing $1 \mathrm{mmol} / \mathrm{l}$ EDTA. The pieces were rinsed for three times and incubated again in the same medium for $5 \mathrm{~min}$ at $37^{\circ} \mathrm{C}$ in a Petri dish on a titling platform (special construction in our own workshop). Thereafter $\mathrm{Ca}^{++}$was added

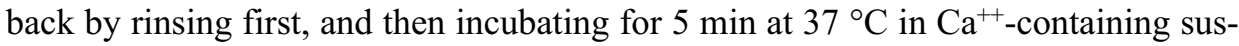
pension buffer (SB) [20]. Removal of $\mathrm{Ca}^{++}$serves the purpose of irreversible weakening of $\mathrm{Ca}^{++}$dependent cell adhesion devices. Readdition of $\mathrm{Ca}^{++}$is necessary for efficient action of collagenase in the following step of isolation because this enzyme is dependent on the presence of $\mathrm{Ca}^{++}$. After the 5 min readdition of $\mathrm{Ca}^{++}$the SB is sucked off and $200 \mathrm{U} / \mathrm{ml}$ collagenase (Sigma Chemical Co.; Collagenase, Type IV for hepatocyte isolation) solution in SB is added to the tissue pieces. An incubation for $20 \mathrm{~min}$ at $37^{\circ} \mathrm{C}$ follows then in the collagenase solution. After the 20 min incubation period the released cells are sucked off as a supernatant together with the collagenase solution. New, unused (or once used and renewed) collagenase solution is added to the tissue pieces remaining in the Petri dish as sediment, and a new round of $20 \mathrm{~min}$ incubation begins. Three or four rounds of this type of incubation in collagenase buffer gave us complete dissociation of the embryonic liver tissue pieces. The supernatant (containing the isolated cells) is filtered through a nylon filter of 250 $\mu \mathrm{m}$ pore size.

The cell content of the suspension was determined and adjusted to the required value with the help of wet weight (w.w.) samples. Hundred $\mu$ l cell suspension was pipetted into preweighed $17 \mathrm{~mm}$ outer diameter (o.d.) glass test tubes (12 cm long). After centrifugation (5 min $3000 \mathrm{rpm}$ ) in a Beckman Spinchron R type refrigerated centrifuge, the supernatant was removed by water blast pump and the tube containing the sediment weighed again. The difference gave the w.w. Incubations of cell suspensions for short-term studies were carried out in $17 \mathrm{~mm}$ o.d. glass test tubes in a shaking water bath (Vibrotherm, Labor MIM, Hungary) at $37^{\circ} \mathrm{C}, 210 \mathrm{rpm}$ as $400 \mu 1$ suspension at around $100 \mathrm{mg} / \mathrm{ml}$ w.w. Short-term primary culturing was carried out in $5 \mathrm{~cm}$ stationary Petri dishes at $37^{\circ} \mathrm{C}$ in a bacteriological thermostate (Labor MIM, Hungary) in SB as a medium, supplemented with antibiotic-antimycotic solution (Sigma Chemical Co.) with a total amount of $15 \mathrm{mg}$ cell (w.w.). The gas phase was air. Either cell type was easily detached from the bottom of the dishes by shaking or with the help of "pipette-jetting".

\section{Electron microscopy}

For electron microscopy of control liver tissue, long thin prismatic pieces with 1-2 $\mathrm{mm}$ shorter dimensions were cut from intact livers. The fixative was SB containing $1 \%$ glutaraldehyde (GA, Reanal, Hungary). Fixation of tissue slices lasted for 1-2 h at room temperature. Fixation of cell suspension was carried out by pipetting the appropriate volume of freshly distilled $10 \% \mathrm{GA}$ into the cell suspension to make $1 \%$ final GA concentration. Other conditions were similar to the tissue slices.

After washing in $0.1 \mathrm{~mol} / 1 \mathrm{Na}$-cacodylate ( $\mathrm{pH} 7.2$, Loba Feinchemie, Austria) 3times (in case of the cell suspension this was carried out with the help of centrifuga- 
tion for $3 \mathrm{~min}$ at $1500 \mathrm{rpm}$ ) embedding of isolated cells followed in $2 \%$ agar (Reanal, Hungary, fermentation quality). Thin slices were cut from the embedded cell suspension for further processing for electron microscopy. Postfixation was carried out in $0.5 \%$ osmic tetroxide in $0.1 \mathrm{~mol} / 1$ cacodylate buffer for $1 \mathrm{~h}$ and staining in $1 \%$ uranyl acetate (Chemapol, Czech Republic) in water for $30 \mathrm{~min}$. After dehydration in graded series of ethanol (Reanal, Hungary) and propylene oxide (Merck, Darmstadt, Germany) samples were embedded in Durcupan (Fluka, Basel, Switzerland).

Ultrathin sections were made by an Om U2 or Ultracut E type ultramicrotome (Reichert, Austria) using diamond or glass knife, contrasted with lead citrate [18] and investigated in a Jeol JEM-100CX-II type electron microscope (Japan) operating at $60 \mathrm{kV}$ accelerating voltage. Morphometric measurements were carried out according to [25].

Acid phosphatase cytochemistry with $\beta$-glycerophosphate (Sigma Chemical Co.) as substrate and $\mathrm{CeCl}_{3}$ (Sigma Chemical Co.) as the trapping agent was carried out as described by [24]. All other chemicals used in our experiments were from Sigma Chemical Co.

\section{RESULTS}

\section{Description of cell types}

The embryonic liver is a more complex tissue than the adult one as it is one of the sites of embryonic blood cell formation from the 9th day of pregnancy in the mouse [5], a close relative of the rat. The 21-day-old rat embryo was chosen as the starting point of a series of later investigations primarily because the liver at this stage is big enough to allow the development of necessary modifications of the cell isolation and incubation method used in in vitro studies of the adult liver cells. To create a firm basis for the identification of cell types in the in vitro experiments we have carried out the basic morphologic and morphometric characterisation of the major cell types of the intact liver tissue of 21-day-old embryos. We distinguished three categories of cells: hepatocytes, erythropoietic cells and the remaining non-identified cell types (Fig. 1).

Hepatocytes in the 21-day-old embryo are cuboidal and their typical maximal dimensions are $15-20 \mu \mathrm{m}$. More than $30 \%$ of their cytoplasmic volume is occupied by glycogen mostly in large confluent areas (Figs 1, 7, Table 1) that can be used as the easiest feature for their identification. In comparison, adult rat hepatocytes have moderate amount (usually a few percent: $1.05 \%$ according to our measurement) of rather scattered glycogen zones (the actual quantity depends on the feeding status of the animal). The maximal length of cross-section of the adult cells is around 20-25 $\mu \mathrm{m}$. It is worth noting that $5 \mu \mathrm{m}$ difference in linear size gives an almost twofold difference in volume. This means that the embryonic hepatocytes are much smaller than the adult ones. 


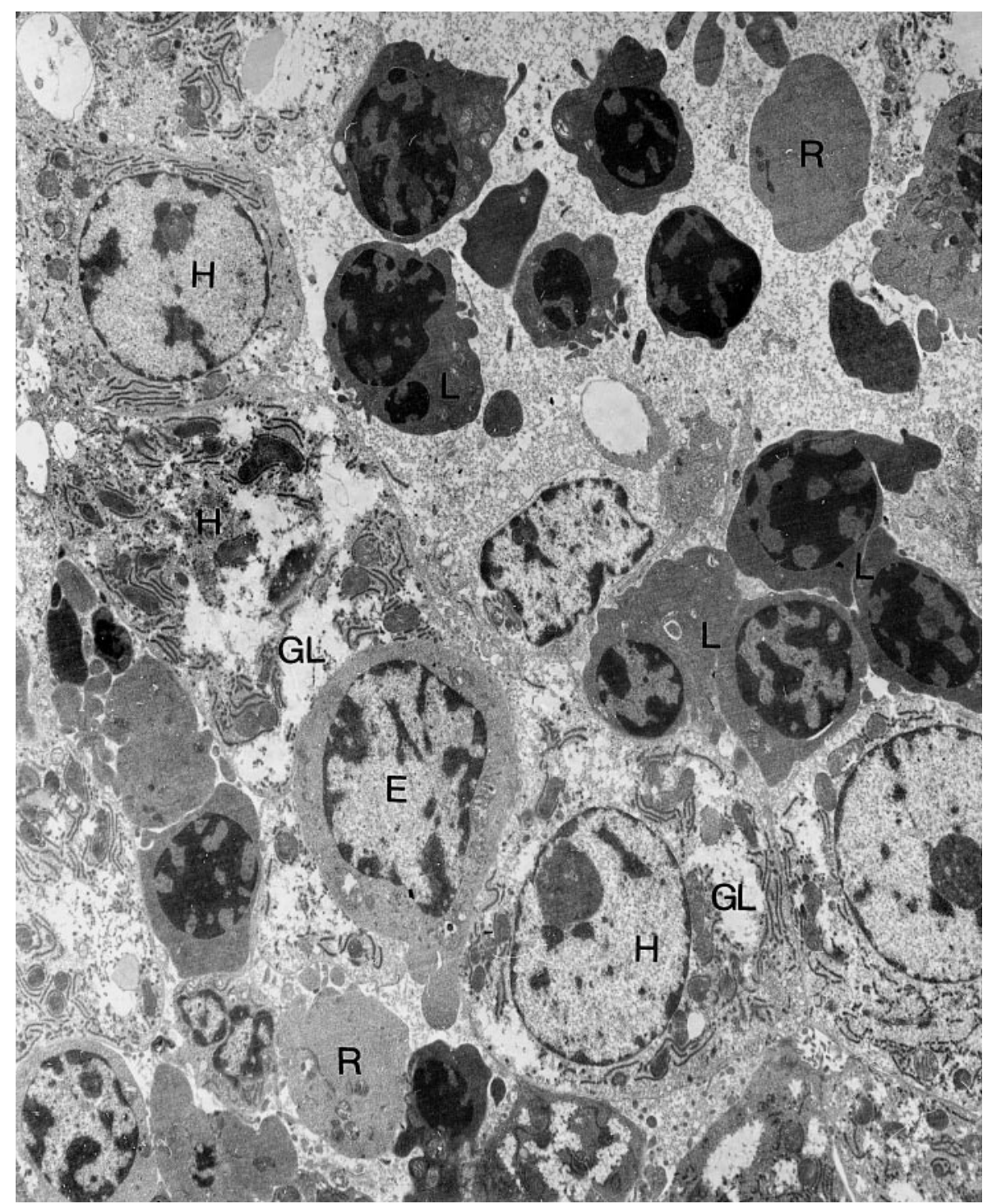

Fig. 1. Liver tissue of a 21-day-old embryo $(\times 3560)$.

$\mathrm{H}$ : hepatocyte, E: early erythroblast, R: reticulocyte, GL: glycogen

Major cell types of the erythropoietic lineage were identified according to the features described by [9]. In early erythroblasts the nucleus is largely euchromatic, the cytoplasm abounds polyribosomes, it contains some cisterns of rough surfaced endoplasmic reticulum (RER), rather large mitochondria and a moderately sized Golgiapparatus. According to our measurements the linear dimensions of these cells are 
close to $10 \mu \mathrm{m}$. Late erythroblasts are usually smaller, they have a rather condensed nucleus that is overwhelmingly heterochromatic, their mitochondria and Golgi-apparatus are also smaller. Reticulocytes have no nucleus, they contain only a few ribosomes, mitochondria and little endomembrane if any (Fig. 1). According to our morphometric measurements hepatocytes in the 21-day-old rat embryo occupy $69.6 \%$ of the total liver volume, early erythroblasts $1 \%$, late erythroblasts $4.64 \%$, reticulocytes $4.15 \%$, mature blood cells $2.32 \%$, non-identified cell types $3.28 \%$, the remaining $15.0 \%$ is extracellular area. No autophagic vacuoles were encountered in hepatocytes, however, we were able to detect a few of them in late erythroblasts and reticulocytes.

The isolation procedure does not change the main morphological features of the above-described cell types which, therefore, can be easily recognised after isolation. Most notable is the fact that isolated hepatocytes retain the high amount of glycogen characteristic for the in vivo state (Table 1). The quantity and quality of the isolated cells produced by our isolation method is totally satisfactory. From the embryos of one pregnant rat we can routinely get several $g$ w.w. of isolated cells (the actual quantity depending on the number of embryos) with more than $95 \%$ viability as measured by trypan blue test.

Table 1

Some morphometric parameters of the hepatocytes of 21-day-old rat embryos

\begin{tabular}{|c|c|c|c|c|}
\hline & $\begin{array}{c}\mathrm{Vv} \\
\text { nucleus }\end{array}$ & $\begin{array}{c}\mathrm{VV} \\
\text { total cytoplasm } \\
\text { (glycogen+functional } \\
\text { cytoplasm) }\end{array}$ & $\begin{array}{c}\mathrm{Vv} \\
\text { glycogen }\end{array}$ & $\begin{array}{c}\mathrm{Vv} \\
\text { functional } \\
\text { cytoplasm }\end{array}$ \\
\hline Hepatocytes in vivo a & 0.1069 & 0.8931 & 0.3104 & 0.6896 \\
\hline $\begin{array}{l}\text { Freshly isolated } \\
\text { hepatocytes }^{\mathrm{b}}\end{array}$ & & 1.0000 & 0.3012 & 0.6988 \\
\hline
\end{tabular}

$V_{v}$ values (expressed as $\mu \mathrm{m}^{3} / \mu \mathrm{m}^{3}$ ) for the nucleus and cytoplasm are related to the total cellular volume; $\mathrm{Vv}$ values of glycogen and functional cytoplasm are related to their sum, i.e. the total cytoplasmic volume. Pictures for morphometry were taken: ${ }^{\text {a }}$ from the samples of intact liver tissue of embryos and a total of $14088 \mu \mathrm{m}^{2}$ tissue area was evaluated; ${ }^{b}$ from the samples of isolated liver cells and a total of $1519 \mu \mathrm{m}^{2}$ cytoplasmic area was evaluated.

\section{Autophagy in hepatocytes}

Autophagic vacuoles can be rarely seen in freshly isolated hepatocytes of the 21-dayold rat embryo although these cells are pre-incubated for over 30 min under conditions which induce the formation of autophagic vacuoles and an increase of lysosomal protein degradation in isolated adult hepatocytes. Incubation for an additional $2.5 \mathrm{~h}$ under similar deprivation conditions in amino acid free SB does not seem to increase the amount of autophagic vacuoles to a significant extent. The rare AVs are rather small and show the usual morphologic appearance (not shown). 


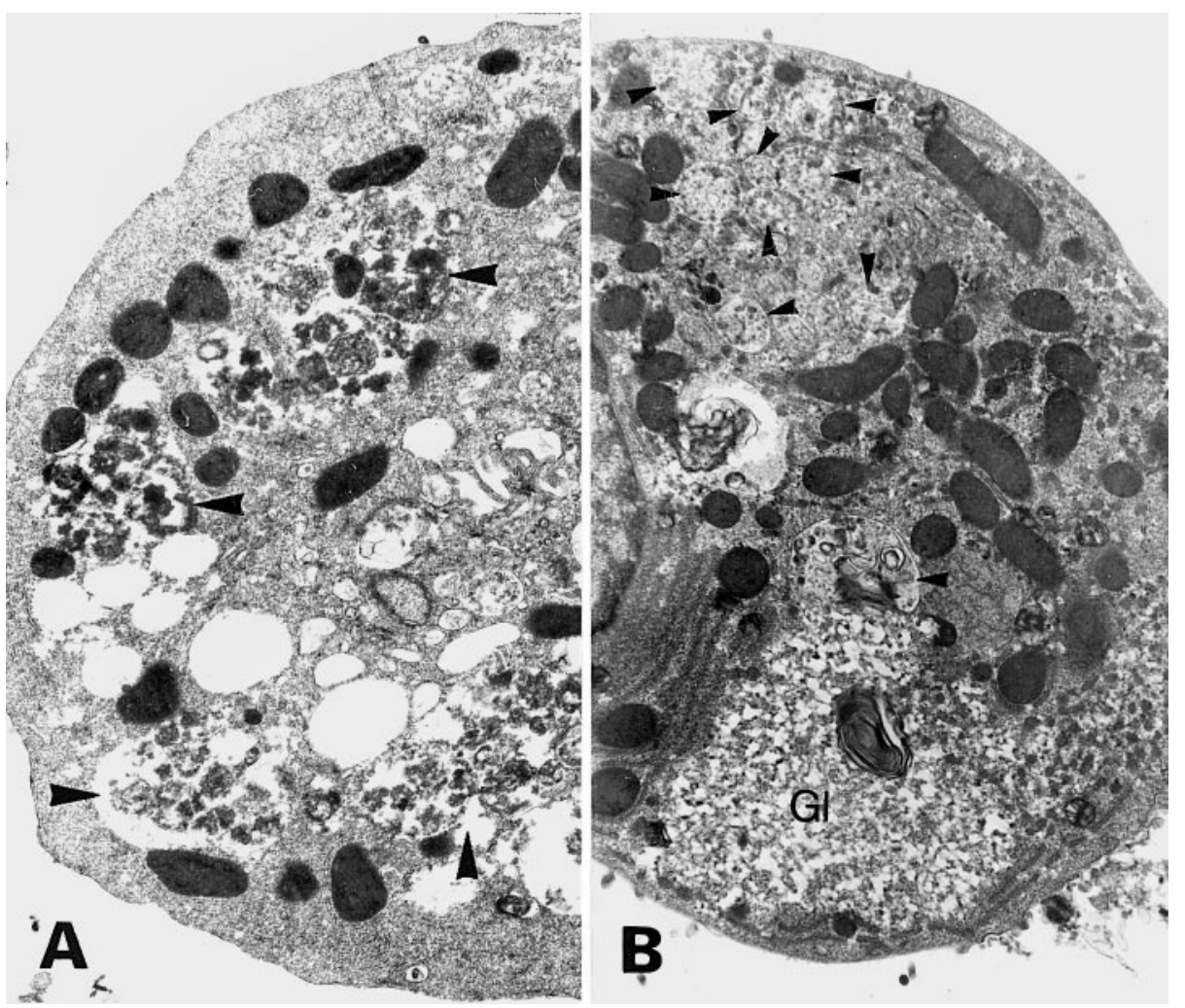

Fig. 2. Isolated hepatocytes after $18 \mathrm{~h}$ primary culture in nutrient-free medium $(\times 10190)$. A: accumulated autophagic vacuoles (large arrowheads) in a cell without addition to the medium; B: preservation of glycogen $(\mathrm{Gl})$, numerous multivesicular bodies (small arrowheads) and lack of autophagic vacuoles in a cell with $10^{-2} \mathrm{~mol} / 13$-methyladenine in the medium

To further expand our knowledge on the responsiveness of isolated embryonic hepatocytes to deprivation conditions, we put the cells into primary culture for $18 \mathrm{~h}$ in nutrient free BSS (SB). Electron microscopic observations show that hepatocytes under these conditions loose almost all of their glycogen content, furthermore, they contain a very large amount of AVs. We could not observe early AVs in these cells. These AVs are predominantly the late type with a lot of partially degraded material in them (Fig. 2A). They look surprisingly uniform morphologically, giving the impression that their age is similar. According to our morphometric measurement $15 \%$ of the cytoplasmic volume can be found in the autophagic compartment in hepatocytes of these $18 \mathrm{~h}$ primary cultures.

Hepatocytes in $18 \mathrm{~h}$ primary cultures with $10 \mathrm{mmol} / \mathrm{dm}^{3}$ 3-methyladenine (3MA; the specific inhibitor of autophagic sequestration [23]) in the medium, show a rather different picture. A lot of glycogen seems to be retained in them and, in parallel, no 
typical AVs can be observed in their cytoplasm. There are, however, vacuolar elements in these cells which in some of the cases contain myelinated material but as a rule show the appearance of the so-called multivesicular bodies (Fig. 2B).

\section{Autophagy in erythropoietic cells}

As mentioned earlier we were able to see AVs in vivo in the cells of the erythropoietic lineage. Their quantity, however, remained rather low even under in vitro conditions. As this is the first time that autophagy is studied in erythropoietic cells of embryonic liver we find it necessary to point out that our observations in vitro show certain morphological features, especially in reticulocytes, that have not been adequately described before in the adult systems [7-9].

Like in other cell types AVs in the erythropoietic lineage are identified as membrane bordered intracytoplasmic bodies that contain recognisable or otherwise identifiable cytoplasmic elements inside them. AVs can be found in early and late erythroblasts (Fig. 3) as well as in reticulocytes (Figs 4-6). The isolation membrane is of the smooth type that is a pair of single membranes separated by an empty-looking narrow space (Figs 4, 5), but occasionally remains attached together and appears as a pentalaminar structure (Fig. 5B). Such membranes can be seen not only encircling cytoplasmic areas completely, but in a few cases also with open ends as if they were in the process of engulfing cytoplasmic portions (Figs 4A, 4C and 5B). It is also necessary to point out that according to serial sections the encircled areas (apart from a

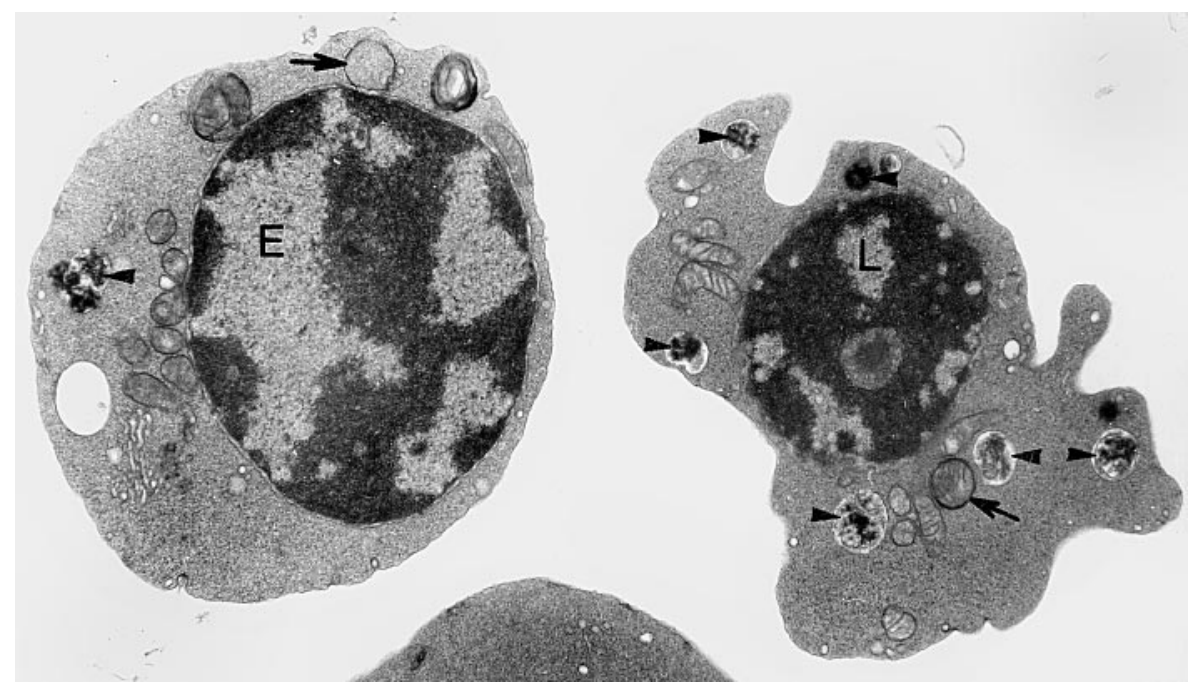

Fig. 3. Freshly isolated early (E) and late (L) erythroblast with early (arrows) and late (arrowheads) autophagic vacuoles in them $(\times 10700)$ 
few exceptions of unclosed isolation membranes mentioned above) are indeed real autophagosomes completely covered in space by the isolation membrane. Sometimes two double membranes surround the same area (Fig. 4E). The size of encircled areas and the content of the vacuoles may vary to a great extent. Sometimes only a single mitochondrion is covered closely or a small amount of additional cytoplasm is also included (Fig. 4D). In many cases only ground cytoplasm is separated (Figs 4E, 4F, $5 \mathrm{~A}, 6 \mathrm{~B})$. In erythroblasts, fragments of ER or small vesicles may also be seen in AVs (not shown). In several occasions big areas of cytoplasm with several mitochondria are engulfed (Figs 4B, 6A). Our observations on the AVs with clearly identifiable content reveal that, with a few exceptions, the isolated material derives from the same stage of development that the cell is in. AVs apparently in the process of exocytosis can be observed both in late erythroblasts and in reticulocytes. The exocytosed material can be both the degraded and the undegraded type (Fig. 6).

The morphology of autophagy in erythropoietic cells in $18 \mathrm{~h}$ primary culture together with the hepatocytes does not show any conspicuous change. We can see
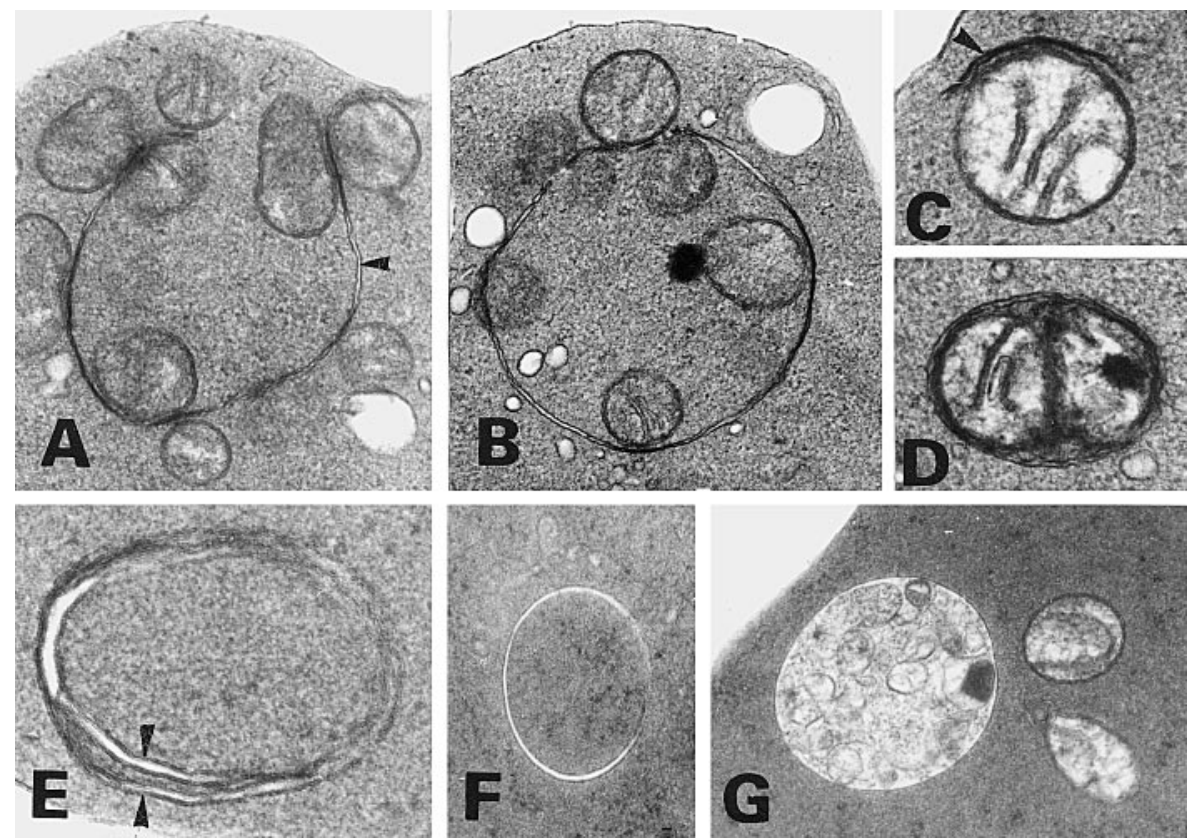

Fig. 4. Autophagy in reticulocytes. A: open isolation membrane (arrowhead) apparently engulfing a large area of cytoplasm $(\times 27270)$. B: large early autophagic vacuole with a lot of ground cytoplasm and several mitochondria inside $(\times 26350)$. C: open isolated membrane (arrowhead) around a mitochondrion $(\times 54000)$. D: autophagic vacuole containing mitochondrion $(\times 43200)$. E: autophagic vacuole bordered by two double isolation membranes (arrowheads) and containing ground cytoplasm $(\times 75000)$. F: ground cytoplasm in relatively large autophagic vacuole $(\times 27910)$. G: autophagic vacuole with highly destructed content probably isolated in an earlier developmental phase $(\times 26110)$ 


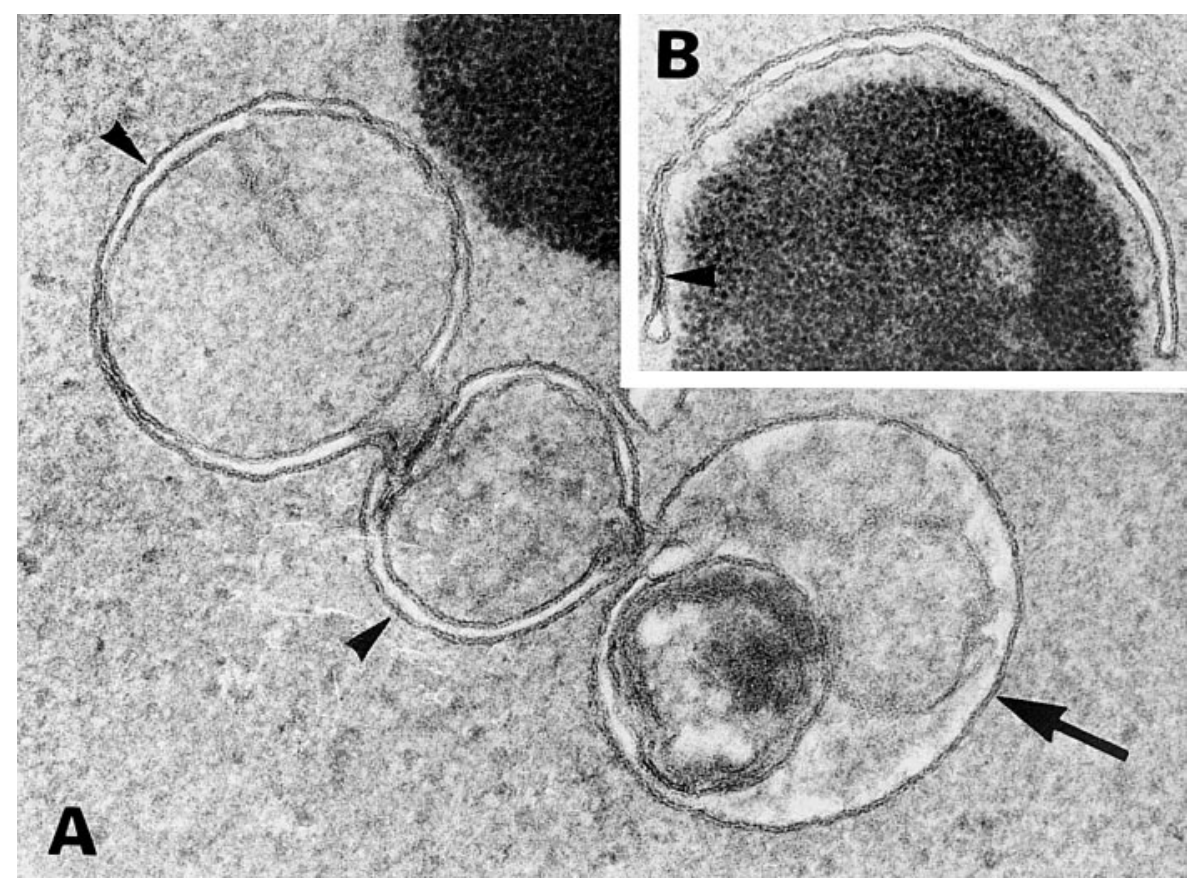

Fig. 5. Autophagy in reticulocyte in an $18 \mathrm{~h}$ culture treated with 3-methyladenine. A: early autophagic vacuoles with double isolation membrane (arrowheads) and a late one with single isolation membrane (arrow) $(\times 107140)$; B: open isolation membrane with pentalaminar structure (arrowhead) $(\times 107$ 140)

dividing erythroblasts in these cultures indicating that the erythropoietic process still goes on. It is, however, quite remarkable that in contrast with hepatocytes we can find early autophagic vacuoles and even unclosed isolation membranes in reticulocytes of $18 \mathrm{~h}$ primary culture treated with 3-MA (Fig. 5).

Enzyme cytochemical reaction for acid phosphatase in isolated cells of livers of 21-days-old embryos demonstrate the presence of this enzyme in freshly isolated hepatocytes in vacuolar elements as well as in the Golgi-apparatus (Fig. 7A). It is noteworthy, however, that several vacuolar-type elements are apparently devoid of enzyme activity.

Cells of the erythropoietic lineage only rarely show acid phosphatase activity (Figs 7B, 7C). The early erythroblast in Fig. 7C shows no sign of enzyme activity either in the Golgi-region or in an early AV, however, there is a positive reaction in a vacuolar element. Vacuolar elements in reticulocytes were, as a rule, devoid of enzyme reaction product (Fig. 7D). 


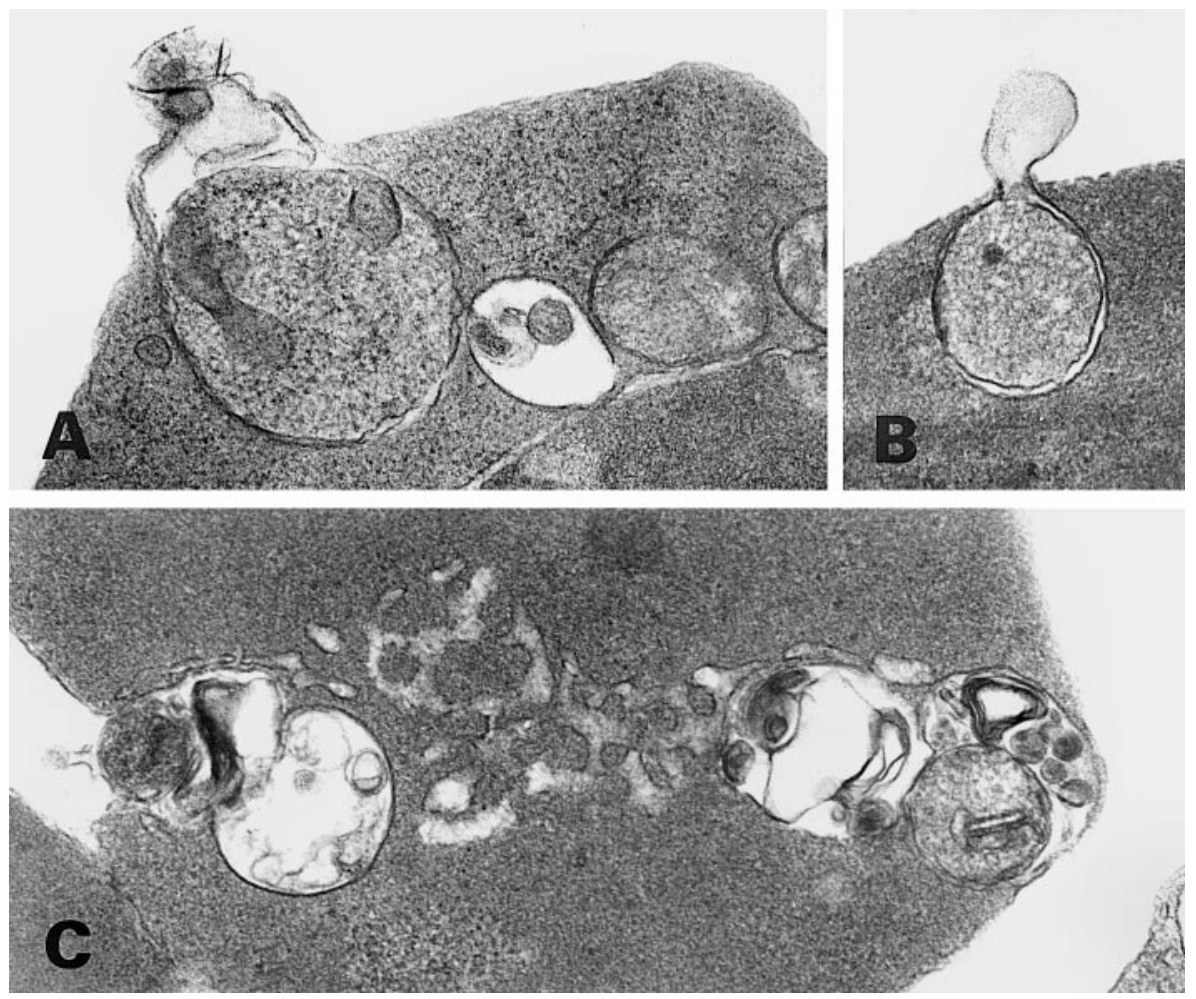

Fig. 6. Exocytosis of autophagic vacuoles. A: early autophagic vacuole in late erythroblast $(\times 38570)$; B: early autophagic vacuole in reticulocyte $(\times 42670)$; C: early and late autophagic vacuoles in reticulocyte $(\times 38630)$

\section{DISCUSSION}

\section{The isolation procedure and the experimental system}

In this study we investigate autophagy in isolated liver cells of the 21-day-old rat embryo for the first time. The prerequisite of this work was the development of an isolation method for producing appropriate suspension of embryonic liver cells. By applying the principles of the two-step perfusion technique of Seglen (based on $\mathrm{Ca}^{++}$ removal and collagenase treatment) [20] for the isolation of adult hepatocytes we developed a non-perfusion method. As a result of our modifications we were able to produce sufficiently high quantity of cell suspension from 21-day-old rat embryos with $95-100 \%$ viability as measured by the trypan blue exclusion test.

We used two types of in vitro experimental systems to study autophagy in the isolated cells. The short-term experiments were carried out in centrifuge tubes in a 37 ${ }^{\circ} \mathrm{C}$ shaking water bath (see Materials and methods). At the routinely applied 100 


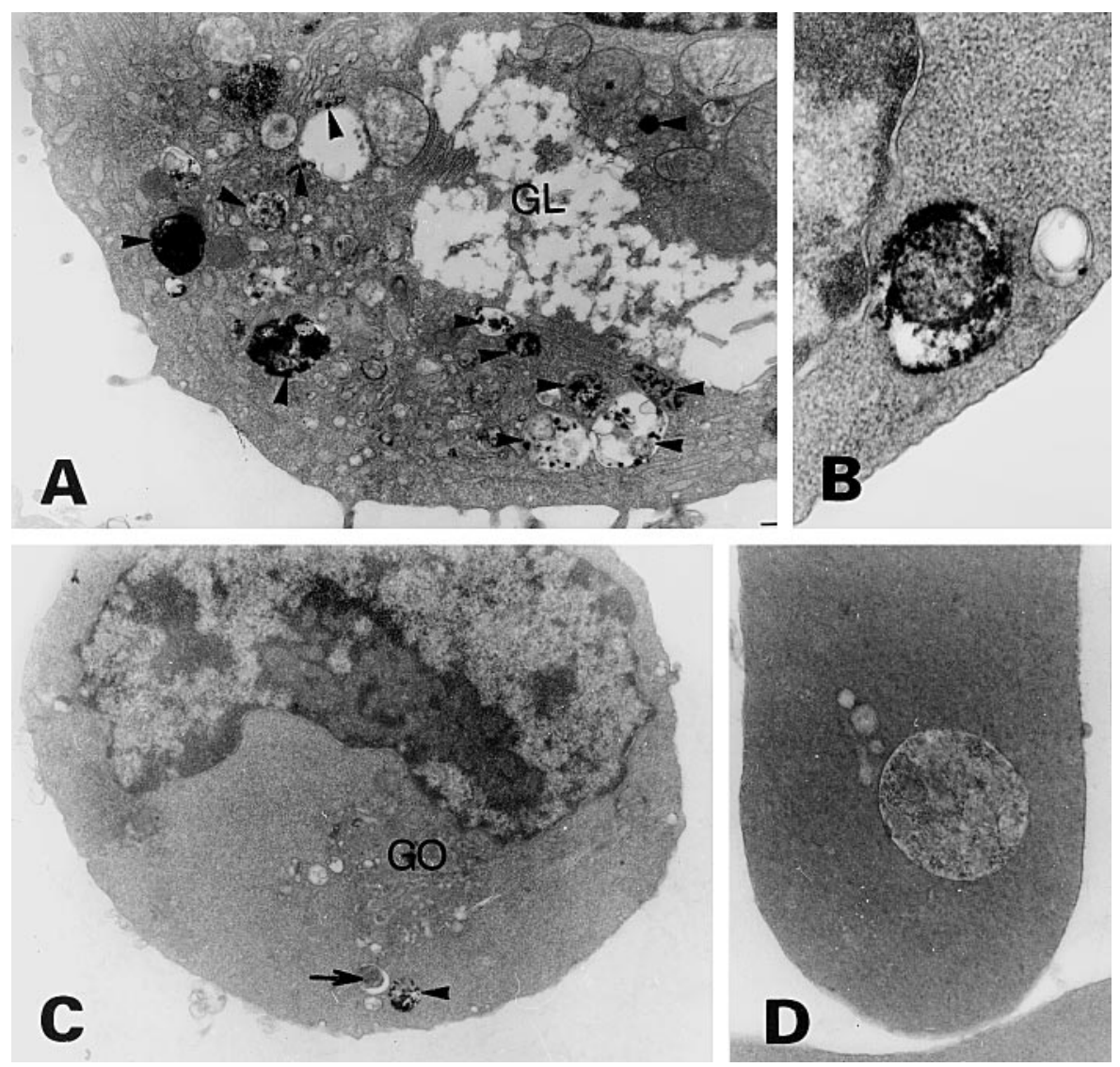

Fig. 7. Acid phosphatase cytochemistry in isolated cells of embryonic liver. A: large area of glycogen (GL) and acid phosphatase positive structures (arrowheads) include both Golgi- and lysosomalelements in a freshly isolated hepatocyte $(\times 8660)$; B: acid phosphatase positive autophagic vacuole in a late erythroblast $(\times 30770)$; C: early erythroblast with no sign of acid phosphatase activity in the Golgi-region (GO) and in an early autophagic vacuole (arrow), activity is shown in a vacuolar element (arrowhead) $(\times 8630)$; D: late autophagic vacuole in a reticulocyte with no sign of acid phosphatase reaction $(\times 19200)$

$\mathrm{mg} / \mathrm{ml} \mathrm{w.w.} \mathrm{density} \mathrm{of} \mathrm{the} \mathrm{suspension} \mathrm{there} \mathrm{was} \mathrm{no} \mathrm{significant} \mathrm{change} \mathrm{in} \mathrm{the} \mathrm{viabili-}$ ty of cells during an experimental time of $2.5 \mathrm{~h}$. However, the rapid shaking exerts mechanical force on the cells and longer treatments cannot be made in this system. For longer experiments, primary cultures of $5 \mathrm{~cm}$ Petri dishes with 10-15 mg w.w. cell samples in them were used. In the primary cultures we saw some $15-20 \%$ cell loss of hepatocytes due to necrotic cell death during $18 \mathrm{~h}$ culture. This probably was the consequence of the starvation medium rather than other factors. Due to the use of HEPES based BSS there was no need for special $\mathrm{CO}_{2}$ thermostate and the cells seem to survive very well with oxygenation by air. 
Our results show the applicability of the isolation technique and the experimental systems for the kinds of studies we have performed. However, further work is needed for more exact characterisation of the conditions if time curves of autophagy are to be studied especially during erythropoiesis.

\section{Autophagy in isolated hepatocytes}

The autophagic activity in hepatocytes in vivo has been shown to depend on the rhythm of food intake [17]. It has been suggested that in case of fasting a main function of autophagy in liver may be the production of amino acids primarily for exporting them into the blood to satisfy the needs of other organs of the body [15]. The initial lack of AVs in freshly isolated embryonic hepatocytes in our work is in contrast with the behaviour of adult isolated hepatocytes where autophagy and protein degradation is operating at full capacity already after $30 \mathrm{~min}$ incubation following isolation [21]. Even $2.5 \mathrm{~h}$ incubation in nutrient free BSS was not enough to activate the autophagic segregation mechanism significantly in these cells. The mammalian embryo develops inside the mother's body in a well-protected environment. Variations in nutrient supply of the embryonic liver are very likely to be much reduced by the mother's homeostatic mechanisms. Our observation that embryonic hepatocytes in vivo are devoid of AVs can be explained by these conditions.

Our enzyme cytochemical reactions show the presence of acid phosphatase (APase) reactions in the Golgi-apparatus and AP-ase positive vacuoles in freshly isolated embryonic liver cells. This is an indication that, although autophagic segregation is depressed, the lysosomal system of these cells is active and prepared for the digestion of prospective substrates.

In contrast, hepatocytes in $18 \mathrm{~h}$ culture in SB showed a very high proportion of $\mathrm{AVs}$ in their cytoplasm. Glycogen content in these cells was practically reduced to zero. Almost all AVs in these cells contained highly electron dense remnants of previously autophagocytosed material that looked morphologically destroyed, but remained largely undigested. However, there were no early AVs with clearly recognisable morphologically unchanged material.

The above observations show that isolated embryonic hepatocytes have the potential to perform autophagic sequestration at a high level but this capability needs longer time to be activated as compared to adult cells. We suggest that in isolated embryonic hepatocytes a large wave of autophagy takes place parallel with or concomitant to the utilisation of glycogen. The lack of early AVs in the $18 \mathrm{~h}$ samples suggests that the hepatocytes seem to be able to shut down this autophagic segregation process at a certain point in time and continue their life with a lot of structurally deteriorated, but biochemically undegraded material in their vacuolar compartment. As the autolysosomes are apparently saturated by the previously sequestered endogenous substrate the speed of degradation at this stage must be limited by the availability of lysosomal enzymes. Downregulation of autophagic sequestration under these conditions may serve two purposes: to save energy as sequestration is an ener- 
gy consuming process, and to preserve the remaining functional cytoplasm to ensure long-term survival. In line with this interpretation we wish to point out that even in the cells of multicellulars autophagy may serve as a survival mechanism not only as a suicidal one emphasised in many earlier reports (see [3] for review).

The lack of macroautophagic vacuoles in 3-MA-treated primary cultures of hepatocytes indicates a long-lasting and complete inhibition of autophagic segregation by this drug. Alternatively, 3-MA might have lost its effectivity earlier during the $18 \mathrm{~h}$ and inhibited only the earlier wave of autophagy. If the latter case is true, it supports the view that the lack of early AVs in the cells means that they themselves have shut down their autophagic segregation pathway. To differentiate between these possibilities further work is needed. The effect of 3-MA on the preservation of glycogen is a new observation for which we cannot offer any explanation yet. The presence of multivesicular body-like vacuoles in the 3-MA-treated cells raises the question if these vacuoles can be microautophagic bodies. It can be envisaged that as the macroautophagic pathway is shut down by 3-MA, the cell tries to compensate the lack of it by a hyperfunction of microautophagy which is a rather interesting possibility for future investigations.

\section{Erythropoietic cells}

According to our observations AVs can be observed in early and late erythroblasts as well as in reticulocytes of the embryonic liver. As pointed out in the Results section the content of early AVs clearly show that sequestration takes place in all stages of erythrocyte development. The most remarkable conclusion from this observation is that even the highly reduced reticulocytes retain the presumably quite complicated sequestration apparatus and can perform the process. As these cells are very much reduced in their morphology as well as in their biochemical activity it is of considerable interest to characterise the sequestration and autophagy in them because we may find several features of these processes unhindered by the complexity of the cellular machinery.

Reticulocytes have no extensive intracellular membrane compartments. They are practically devoid of typical RER which is the membrane type considered by several authors to be the source of the autophagic isolation membrane (see [16] for review). The fact that isolation membranes still emerge in these cells support the argument of those who suggest that the isolation membrane may arise de novo and not by direct transformation from other preformed membranes [13]. The presence of unclosed isolation membranes and early $\mathrm{AVs}$ in 3-MA treated reticulocytes as opposed to their absence in hepatocytes in $18 \mathrm{~h}$ primary culture raises the intriguing possibility that segregation in reticulocytes is insensitive to this drug, although the alternative explanation mentioned above for hepatocytes also has to be taken into consideration.

Our enzyme cytochemical reactions indicate a low occurrence of AP-ase activity in the erythropoietic cell types. AVs in reticulocytes in particular seem to be highly 
reduced or even devoid of AP-ase reaction product. The low AP-ase reactivity is in good accordance with the high frequency of early AVs containing morphologically unchanged segregated material. We see in our material and know from the literature [7] that exocytosis of the autophagically sequestered material occurs in reticulocytes rather frequently. We suggest that the developing erythrocytes compensate for the reduction of lysosomal enzymes with the exocytotic activity as a means of getting rid of the autophagically sequestered material.

In the literature the attention has been focused mainly on the selective elimination of mitochondria in reticulocytes [8]. Our observations show that in many cases mitochondria indeed seem to be the only content of autophagic vacuoles. There are, however, also many occasions where only ground cytoplasm is separated, therefore, elimination of mitochondria cannot be the only purpose of autophagy in reticulocytes.

Erythropoiesis is well characterised in many respects, and the new, modified isolation method published here make both erythropoietic cells and hepatocytes easily available from the rat embryo. Our results show that both cell types show interesting new features that make them promising objects for extending our knowledge on the process of autophagy.

\section{ACKNOWLEDGEMENTS}

The skilful technical assistance of Mrs. E. Pálmai, Mrs. K. Petrovics and Ms. A. Keserü is gratefully acknowledged.

\section{REFERENCES}

1. Altmann, P. L., Dittmer, D. S. (1968) Metabolism. Federation of American Societies for Experimental Biology, Bethesda, Maryland.

2. Blommaart, E. F. C., Luiken, J. J. F. P., Meijer, A. J. (1997) Autophagic proteolysis: control and specificity. Histochem. Jour. 29, 365-385.

3. Clarke, P. G. H. (1990) Developmental cell death: morphological diversity and multiple mechanisms. Anat. Embryol. 181, 195-213.

4. Dunn, W. A. Jr. (1994) Autophagy and related mechanisms of lysosome-mediated protein degradation. Trends in Cell Biol. 4, 139-143.

5. Dzierzak, E., Medvinsky, A. (1995) Mouse embryonic hematopoiesis. Trends in Genetics 11, 359-366.

6. Fengsrud, M., Roos, N., Berg, T., Liou, W., Slot, J. W., Seglen, P. O. (1995) Ultrastructural and immunocytochemical characterisation of autophagic vacuoles in isolated hepatocytes. Effects of vinblastine and asparagine on vacuole distributions. Exp. Cell Res. 221, 504-519.

7. Gronowicz, G., Swift, H., Steck, T. L. (1984) Maturation of the reticulocyte in vitro. J. Cell Sci. 71, 177-197.

8. Heynen, M. J., Tricot, G., Verwilghen, R. L. (1985) Autophagy of mitochondria in rat bone marrow erythroid cells. Relation to nuclear extrusion. Cell Tissue Res. 239, 235-239.

9. Heynen, M. J., Verwilghen, R. L. (1982) A quantitative ultrastructural study of normal rat erythroblasts and reticulocytes. Cell Tissue Res. 224, 397-408.

10. Kisen, G. O., Tessitore, L., Costelli, P., Gordon, P. B., Schwarze, P. E., Baccino, F., Seglen, P. O. (1993) Reduced autophagic activity in primary rat hepatocellular carcinoma and ascites hepatoma cells. Carcinogenesis 14, 2501-2505. 
11. Klionsky, D. J., Ohsumi, Y. (1999) Vacuolar import of proteins and organelles from the cytoplasm. Ann. Rev. Cell. Dev. Biol. 15, 1-32.

12. Kovács, A., Kovács, J. (1977) Cellular autophagocytosis in mouse seminal vesicle cells in vitro. Acta Biol. Acad. Sci. Hung. 28, 415-423.

13. Kovács, A. L., Réz, G., Pálfia, Z., Kovács, J. (2000) Autophagy in the epithelial cells of murine seminal vesicle in vitro: formation of large sheets of nascent isolation membranes, sequestration of the nucleus and inhbition by wortmannin and 3-methyladenine. Cell Tissue Res. 302, 253-261.

14. Mortimore, G. E., Pösö, A. R., Lardeux, B. R. (1989) Mechanism and regulation of protein degradation in liver. Diabetes/Metabolism Rev. 5, 49-70.

15. Mortimore, G. (1987) Mechanism and regulation of induced and basal protein degradartion in liver. In: Glaumann, H., and Ballard, F. J. (eds) Lysosomes: Their Role in Protein Breakdown. Academic Press, London, pp. 415-443.

16. Pfeifer, U. (1987) Functional morphology of the lysosomal apparatus. In: Glaumann, H., and Ballard F. J. (eds) Lysosomes: Their Role in Protein Breakdown. Academic Press, London, pp. 3-59.

17. Pfeifer, U. (1972) Inverted diurnal rhythm of cellular autophagy in liver cells of rats fed a single daily meal. Virchows Arch. Abt. B Zellpath. 10, 1-3.

18. Reynolds, E. S. (1963) The use of lead citrate at high $\mathrm{pH}$ as an electron-opaque stain in electron microscopy. J. Cell Biol. 17, 208-212.

19. Réz, G., Tóth, S., Pálfia, Z. (1999) Cellular autophagic capacity is highly increased in azaserineinduced premalignant atypical acinar nodule cells. Carcinogenesis 20, 1893-1898.

20. Seglen, P. O. (1976) Preparation of isolated rat liver cells. Methods Cell Biol. 13, 29-83.

21. Seglen, P. O. (1987) Regulation of autophagic protein degradation in isolated liver cells. In: Glaumann, H., and Ballard, F. J. (eds) Lysosomes: Their Role in Protein Breakdown. Academic Press, London, pp. 371-414.

22. Seglen, P. O., Bohley, P. (1992) Autophagy and other vacuolar protein degradation mechanisms. Experientia 48, 158-172.

23. Seglen, P. O., Gordon, P. B. (1982) 3-Methyladenine specific inhibitor of autophagic/lysosomal degradation in isolated rat hepatocytes. Proc. Natl. Acad. Sci. USA 79, 1889-1892.

24. Van Noorden, C. J., Frederiks, W. M. (1993) Cerium methods for light and electron microscopical histochemistry. J. Microsc. 171, 3-16.

25. Williams, M. A. (1977) Quantitative studies in biology. In: Glauert, A. M. (ed.) Practical Methods in Electron Microscopy, Vol. 6. Part II, North-Holland Publ. Co., Amsterdam, New York, Oxford. 